\title{
DESCRIPCIÓN Y ANÁLISIS DE UNA EXPERIENCIA DE GARANTÍA SOCIAL
}

\author{
Jesús Jiménez Martínez \\ Maestro del CRA Cameros Nuevo
}

\begin{abstract}
RESUMEN. Los programas de Garantía Social cumplen en la actualidad una función social importante. Existe un número determinado de alumnos/as que, al finalizar su escolaridad obligatoria, no han tenido la posibilidad de acceder al título de Graduado en Educación Secundaria por muy diferentes y diversas razones. Ello les lleva, en principio, a una situación personal y laboral muy delicada. El sistema educativo actualmente en funcionamiento observó que existía esta posibilidad y se planteó, de una manera responsable, establecer los mecanismos necesarios para que todo este alumnado recibiera una formación que le permitiera acceder al mundo laboral con unas posibilidades reales de encontrar un trabajo digno.

Pero, lo más importante de todo esto no es la existencia de esta posibilidad que lo es, sino el que esto se lleve adelante con la máxima calidad posible. Hablar de calidad en educación es hablar de muchos aspectos de tipo personal y material. No voy a entrar a discutir en qué consiste la calidad en educación. Simplemente pretendo expresar por escrito todo aquello que a mí en un momento dado me ha servido en el aula y concretamente en un programa de Garantía Social.
\end{abstract}

ABSTRACT. Nowadays "Garantía Social" Programmes carry out an important social task. Certain number of pupils are not able to get the school-leaving certificate when they finish their compulsory attendance at school. There are many and different reasons that explain this fact. The personal and work situation is really delicate for these young people. Our present educative system realized a solution was possible and in a responsible way, it was thought to establish the necessary steps for all these pupils received occupational training. This would let them have access to the work world and find a decent job.

The most important thing is not only the existence of this possibility but the aim to go ahead with the project trying to manage the highest quality. Speaking of educative quality is speaking about personal and material aspects. I do not want to discuss what "quality" means in terms of education. I only try to write about all that was very use ful for me in my classroom and, particularly, in a "Garantía Social" Programme.

¿Qué he de hacer? ¿Por dónde empezar? ¿Cómo hacerlo? Estas, entre otras muchas, son las cuestiones que cualquier docente se plantea en el momento en que se encuentra con una serie de alumnos/as, que, más que nunca, están a la expectativa sobre este nuevo producto que le acaban de vender: la Garantía Social. Esta reflexión que pongo en tus manos sobre los programas de Garantía Social pretende, en 
cierta medida, dar respuesta a esas cuestiones. Ahora bien, quiero dejar muy claro, antes de empezar con su lectura, que aquí no hay recetas mágicas, solamente reflexión acerca de siete años de trabajo con alumnos/as con problemas, que no problemáticos.

Me gustaría que, al finalizar esta reflexión, quedara clara la importancia que hemos de dar en estos programas a la formación personal. Es importante la parte cultural y académica, es más importante la parte correspondiente a la Formación Profesional Específica, pero es de vital importancia para nuestros alumnos/as su formación como personas. Todos ellos llegan a estos programas con una autoestima pulverizada por muchos años de fracasos de todo tipo: familiares, personales, escolares y sociales. Ha llegado el momento de recomponer el puzzle. Nos ha tocado a nosotros intentarlo. Una cosa ha de quedar claro, la tarea es difícil, pero hemos de intentarlo. Es una de sus últimas oportunidades antes de salir al mundo. Con uno de ellos que lo aproveche, nos hemos de sentir satisfechos. Lógicamente desde un punto de vista económico no es rentable pero sí lo es individual y socialmente.

Estos alumnos/as nos necesitan mucho y, por lo tanto, hemos de intentar tener nuestras mentes abiertas y despiertas para guiarles por el camino que consideramos correcto, aun a sabiendas de que se pueden salir de él en cualquier momento del trayecto. No podemos olvidar que, después de estar en las aulas con nosotros durante seis horas, vuelven a su lugar, a su ambiente, a su calle, a sus amigos... Seguramente estarán muy contentos y satisfechos con los compañeros y profesores del programa. Con toda certeza, les entusiasmará el taller, bien es verdad que unos días más que otros. Estoy convencido que disfrutarán en el centro como nunca lo han hecho. Ahora bien, aun con todo ello, posiblemente tenemos las de perder.

Por último, quisiera añadir una última reflexión en este prólogo. Una reflexión que tiene que ver especialmente con el aspecto formativo de los docentes. Me gustaría, desde estas páginas, animar a todos los docentes, sean del nivel que sean, a reflexionar sobre su tarea diaria, sobre el día a día en las aulas. Es, en mi opinión, el comienzo de una buena y adecuada formación permanente. Sin duda, será necesario realizar cursos de formación en los centros previstos, pero si ello no va acompañado de una puesta en práctica y de una posterior y profunda reflexión sobre la misma, poco habremos logrado. En el caso que nos ocupa, los programas de Garantía Social, es imprescindible una formación inicial, en la que se analicen con profundidad su estructura, tipología de alumnos y, sobre todo, metodologías y principios de organización. Pero, no podemos ni debemos quedarnos ahí. Estas jornadas iniciales suelen ser un bombardeo de información sobre los docentes. Uno acaba con la sensación de estar más desorientado que cuando los inicia. Por ello, es muy importante establecer unos grupos de trabajo permanentes con el fin de ir interiorizando y asimilando poco a poco todo esa información anterior. Este proceso formativo nunca tendrá fin. Veremos más luz, estaremos más seguros de lo que hacemos, pero seguiremos reflexionando sobre nuestra actividad docente y continuaremos mejorando nuestro proyecto formativo. Es, en mi opinión, el único proceso de formación realmente válido.

Es el binomio REFLEXIÓN-ACCIÓN, uno de los principales elementos en la formación de los docentes, lo demás son méritos. 


\section{Los programas de Garatía Social}

La orden que regulan los programas de Garantía Social es del día 12 de Enero de 1993. (BOE del 19 de Enero de 1993).

El marco legal de referencia de la orden anterior está determinado por el artículo 23 de la LOGSE, por el artículo 14 del Real decreto 1007/1991 que establece las enseñanzas mínimas de la E.S.O. y por el artículo 20 del Real Decreto 1345/1991 que establece el currículo de dicha etapa en el territorio de gestión del Ministerio de Educación y Ciencia.

\subsection{Alumnado}

Los programas de Garantía Social están destinados a jóvenes menores de 21 años que, al menos, cumplan 16 en el año natural en que inician el programa y no hayan alcanzado los objetivos de la Educación Secundaria Obligatoria ni posean titulación alguna de Formación Profesional.

\subsection{Finalidad}

Tal y como viene recogido en dicha orden, la finalidad de este tipo de programas es doble.

Por una parte, se trata de proporcionar a este tipo de alumnos/as una formación básica y profesional que les permita incorporarse al mundo laboral. Realmente, la mayoría de los alumnos/as que acuden a estos programas lo hacen como una última solución. Han acabado su escolaridad obligatoria y se encuentran a las puertas de la vida. Es el momento de reconocer que no han dado todo lo que tenían, que, en muchos de los casos, han perdido un tiempo precioso y que no tienen una mínima formación para enfrentarse al mundo del trabajo. Por ello, la mayor parte de nuestros alumnos/as quieren aprovechar este tiempo que se les ofrece para, al menos, terminar su escolaridad con la adquisición de unas capacidades mínimas relacionadas con una profesión. El mundo laboral está bastante mal y ellos saben que, si tienen serias dificultades los que han obtenido algún tipo de título, ellos las doblan. Por tanto, es su oportunidad.

Una segunda finalidad, señalada por la orden de 13 de enero, habla de la posibilidad de insertar, de nuevo, a estos alumnos/as en el sistema educativo a través de una prueba de acceso.

Esta es una puerta a la esperanza para algunos alumnos/as que han tenido dificultades en su escolaridad por razones diferentes a las de su capacidad, generalmente razones de tipo familiar, social y de inmadurez personal.

\subsection{Objetivos de los programas de Garantía Social}

En tres grandes bloques podemos agrupar los objetivos que se pretenden conseguir con este tipo de programas.

En primer lugar, ampliar la formación de los alumnos/as en cuanto a la adquisición de capacidades propias de la enseñanza básica. La mayor parte de estos alumnos/as 
tienen un nivel bastante bajo. Su principal problema ha sido la desmotivación y el desinterés por los temas escolares. Ello les ha llevado a que, adquiridos los aprendizajes básicos en las materias instrumentales, todo lo demás no ha sido asimilado ni interiorizado, en todo caso han sufrido un cierto retroceso.

En segundo lugar, nos encontramos con que tenemos que conseguir unos objetivos que tienen que ver con el perfil profesional. Estos objetivos son, sin lugar a dudas, muy importantes. Al fin y al cabo, estos alumnos/as acceden a estos programas por el oficio o profesión que desean aprender. A la hora de trabajar estos objetivos, tenemos de ventaja que los alumnos/as, en principio, están muy motivados con el taller, lo cual supone, para empezar, eliminar todo atisbo de indisciplina en el aula. Aspecto este que más problemas puede causar en estos programas.

En tercer lugar, nos encontramos con aquellos objetivos que tienen que ver con la formación personal de estos alumnos/as, con su madurez personal. Son, sin duda, los más importantes. Conseguidos estos, estoy convencido que el camino para la adquisición de los otros estará más llano. Realmente, lograr estos objetivos, es la clave para el éxito de estos alumnos/as y, por tanto, de estos programas. Es fundamental que la tutoría sea algo continuo.

\subsection{Estructura de los programas}

La estructura de los programas viene marcados por la orden a la que nos referimos. No obstante, hay que determinar en cada una de las áreas un número de horas, ya que el Ministerio solamente marca un horario aproximado.

En el área de Formación Profesional Específica señala un abanico entre 15 y 18 horas semanales. Es la parte más importante del programa. Están ahí por eso.

En el área de Formación Básica plantea el Ministerio una horquilla entre seis y nueve horas. Esta área es la más dura para los alumnos/as. Para ellos, esto es lo de la "escuela", aquello que tanto odiaron, aquello que nunca fueron capaces de digerir, aquello que tantos quebraderos de cabeza les supuso, tantos castigos, tantos suspensos, etc. Por tanto, los maestros/as responsables de la parte cultural, tenemos una ardua y dura tarea, que los alumnos/as sean capaces de entender y comprender la necesidad de trabajar estos aspectos, que lo hagan con interés y que, además, les enriquezca cultural y personalmente.

El Área de Formación y Orientación Laboral es, a mi juicio, una de las materias más importantes, sobre todo en aquellos programas cuya finalidad sea claramente el mundo laboral. Es un área que puede enganchar, a pesar de todo, muy bien a los alumnos/as, pues da pie a realizar muchas charlas, entrevistas y salidas al entorno. Estas actividades les satisface mucho a los alumnos/as. Es muy positivo, para ellos y para los profesores, que de vez en cuando sean otras personas quienes les cuenten la "historia". Es una forma de dar credibilidad a lo que nosotros, los maestros/as, decimos y explicamos continuamente. Los expertos, si así se les puede llamar, vienen de fuera, de la vida diaria y son los que les van a decir a nuestros alumnos/as cómo está la vida en esos momentos. Hay que traer al fontanero, al empresario pero también a la abuela del pueblo, al ex-alumno/a que está en el paro y al que trabaja, al padre que 
trabaja y al que está de paro. Eso les gusta y les hace aprender más que cualquier lección teórica.

El tiempo dedicado a Tutoría, en mi opinión, ha de ser de dos horas, sobre todo durante el primer trimestre. Me explicaré. El comienzo en estos programas es bastante complejo y difícil, entre otras cosas, porque estos alumnos/as tienen una serie de hábitos y comportamientos adquiridos que, antes de nada, hay que modificar, si queremos que los resultados, al finalizar el curso, sean positivos. Por ello, durante el primer trimestre o el tiempo que se crea oportuno hay que dedicar esas dos horas que el MEC propone. No obstante, los aspectos relacionados con la tutoría, como son las relaciones interpersonales, comportamientos y disciplina son algo que no podemos olvidar en ningún momento de los que estamos con estos alumnos/as. La persona, cada uno de ellos, es lo importante. Lo demás, cultura y taller, tiene una importancia relativa. Lo demás todavía tiene tiempo. Sin embargo, se acaba el tiempo de la recuperación de esos alumnos/as con dificultades personales, familiares y sociales. Todo profesor que se implique en este tipo de programas, ha de hacerlo con la vista puesta en la formación personal de sus alumnos/as. Todo lo demás vendrá por añadidura. Esto es lo importante: ayudarles a salir a flote como personas. Si nos enfrascamos en una batalla de contenidos académicos y nos olvidamos de lo demás, si no existe un acercamiento a la persona con toda su problemática, entonces, estaremos perdiendo el tiempo nosotros y ellos, algo que llevan haciendo ya desde hace mucho. Y, realmente, quizás a nosotros no nos importe perder el tiempo, pero para ellos el tiempo es muy importante.

El MEC marca, también, dos horas dedicadas a actividades Complementarias. Éstas tienen que ver sobre todo con actividades deportivas, culturales y sociales. Por otra parte, los alumnos/as han de participar con sus compañeros del Instituto en actividades complementarias y extraescolares programadas por el Departamento correspondiente.

\section{La Garantía social en los centros. Su planificación}

Hay un aspecto que es necesario tener en cuenta a la hora de organizar un programa de Garantía Social, éste es la relación de dicho programa con el centro, es decir, su inclusión en lo que podríamos denominar "organigrama del centro". Realmente es muy difícil establecer unos criterios mínimos acerca de este aspecto. Yo simplemente quiero abordar algunos puntos que considero que son importantes y que habría que tener en cuenta para que estos programas se integren de forma adecuada en los centros.

En primer lugar, tengo que decir que estos programas, en los momentos actuales, se encuentran un tanto deslavazados de lo que es el organigrama del centro. Muchas son las razones que han permitido esta situación. Ahora bien, yo encuentro una sobre todo. Estos alumnos/as han causado, en líneas generales, bastantes dificultades en los centros durante su escolaridad por muy diversas y variadas razones que no vamos a señalar ahora. Esto hace que la Garantía Social se vea, por una parte de la comunidad educativa, como algo añadido al centro y con pocas expectativas de éxito. 
Hay que trabajar, desde todos los sectores, para que la comunidad educativa, toda ella y sin exclusión, sienta la necesidad de formar convenientemente a todos y cada uno de sus alumnos/as. Yo me atrevería a afirmar que los alumnos/as que son o pueden ser objeto de un programa de Garantía Social, necesitan una formación más completa, si cabe. Estos programas han de surgir como una necesidad. Es el propio claustro quien lo ha de sentir necesario, no por él sino por los alumnos/as a los que va dar una respuesta, que se considera la más digna.

Aún siendo la comunidad educativa quien lo solicite, el trabajo de integración de estos programas es complejo. La mejor fórmula para lograrlo es realizar un trabajo serio y de calidad en el aula, tanto de taller como de cultura. Y ello ha de traspasar la frontera de las aulas del programa. El centro y toda la comunidad educativa ha de vivenciar ese trabajo de calidad. Por ello el profesorado tiene una ardua y difícil tarea en ese sentido Es muy importante, y forma parte de la estrategia global de recuperación de estos alumnos/as, implicarles en el mantenimiento o acondicionamiento de espacios, dependencias o instalaciones. En esta misma línea, hay que hacer especial hincapié en la necesidad de que estos alumnos/as sean una aula más del centro con todas sus consecuencias. Es importante que participen en todas las actividades extraescolares y complementarias que se organicen en el centro. Es necesario que mantengan relación con sus antiguos compañeros y sigan relacionándose con ellos en diferentes actividades. Pero es fundamental que el resto de la comunidad educativa lo vean también así. Por ello, desde el profesorado, se ha de trabajar a conciencia este asunto. Hemos de participar activamente en la vida del centro y hemos de hacernos ver en las diferentes manifestaciones y actividades complementarias que se organicen.

Por parte del centro, a su vez, se ha de ver seriedad y coherencia. Estos programas han de ser mimados. Ser mimados quiere decir, por una parte, reconocer el trabajo que todos, alumnos/as y profesorado, están llevando a cabo y, por otra, permitir una cierta flexibilidad en cuanto a la organización general del programa se refiere. Esto implica, entre otras muchas cosas, dar un margen de confianza a su profesorado en temas tan espinosos como horarios, grupos de trabajo, sistemas disciplinario, elaboración de programaciones, actividades extraescolares, salidas, etc.

No obstante, por todo lo anterior y por esa flexibilidad que comentamos, es necesario que el Equipo Directivo controle en todo momento la situación de los diferentes aspectos que conforman estos programas con el fin de que los alumnos/as estén recibiendo en cada momento lo que realmente necesitan. Se corre el peligro de que, al estar un tanto al margen, nadie los controle. Estos alumnos/as han de recibir una formación más seria y profunda que el resto.

Todo lo anterior nos lleva a pensar que es fundamental, para el éxito de estos programas y, por tanto, de su alumnado, que los centros planifiquen al mínimo detalle su implantación. Es muy importante poner unas bases adecuadas y firmes en el ámbito de todo el centro. Es muy importante y clave para estos programas que surjan como una necesidad del centro y, más concretamente, de los alumnos/as que acuden al mismo. No puede ser algo añadido, algo con lo que la administración nos ha hecho "tragar". Si desde el centro se tiene esa sensación, estoy seguro y convencido que el fracaso está próximo. La más triste es que quien se siente fracasado no es el centro, como así debiera ser, sino el profesorado que imparte docencia en dicho programa. 
En definitiva, la puesta en marcha de estos programas en los centros se ha de hacer desde una perspectiva general y global que ha de tener el Claustro, el Equipo Directivo y el Consejo Escolar. Se trata de pensar en el alumnado que tenemos en nuestros centros y comprender si estos programas les sirven y ayudan o, por el contrario, no le van a suponer ningún beneficio en su formación personal y profesional. Todo lo demás es pura demagogia.

A la hora de planificar la implantación de un programa de Garantía Social en un Centro, es necesario reflexionar sobre toda una serie de cuestiones que permitirán pensar a toda la comunidad educativa que no nos vamos a equivocar con ello. El primer aspecto a tener en cuenta es reflexionar acerca del alumnado con el que contamos en nuestro centro, con sus características, sus problemas, sus posibilidades, etc. Una vez detectados todos los casos, se ha de reflexionar entre todos, Departamento de Orientación y Equipos Docentes sobre todo, cuál puede ser la mejor solución a los problemas planteados. Con toda seguridad, una de las soluciones, en muchos centros, será la puesta en funcionamiento de un programa de este tipo. Esta primera aproximación es importante, pero todo ello ha de ser corroborado con los informes correspondientes. Será el momento de poner en marcha la máquina.

Con relación al alumnado es necesario que el centro tenga establecidos con mucha claridad el PERFIL de los que son sujetos de estos programas con el fin de que los equipos docentes, cuando realicen su orientación, no tengan dudas. Además, es importante que todos tengan claro el PROCESO que se ha de seguir para que el o los alumnos/as propuestos accedan a dicho programa. Clave para el buen funcionamiento del programa es también el PERFIL PROFESIONAL seleccionado. El MEC marca una serie de perfiles profesionales entre los que hemos de optar. En este sentido, el centro ha de reflexionar sobre el más adecuado para nuestros alumnos/as. La comunidad educativa ha de buscar dicho perfil profesional teniendo en cuenta varios aspectos. En primer lugar, es muy importante tener presente las posibilidades de inserción laboral de los alumnos/as que finalicen el programa. Como segundo elemento a tener en cuenta, hemos de pensar en las posibilidades educativas del perfil a seleccionar. Como último elemento de reflexión, tendríamos que pensar, antes de seleccionar uno $\mathrm{u}$ otro perfil, en que todos los alumnos/as, independientemente de su sexo, puedan acceder al programa de Garantía Social elegido. Esto es bastante complicado en muchos casos.

Otro aspecto, que debe tener en cuenta un centro a la hora de planificar un programa de este tipo, es el ESPACIO Y RECURSOS que, por su parte, debe poner sobre la mesa.

Por otra parte, el centro ha de tener muy claro todo lo relacionado con el profesorado que ha de impartir docencia en estos programas. Se ha de buscar, por parte de los centros, que el profesorado tenga el perfil adecuado para ello. Es necesario hacer ver a la administración que este profesorado, tanto de taller como del apartado cultural, ha de estar bien preparado para poder llevar a buen término estos programas y con estos alumno/as. En este sentido es muy interesante la formación inicial y continua de los mismos. Asimismo, se ha de favorecer que el profesorado que imparte docencia en estos programas sea el mínimo posible. Estamos hablando de un tipo de alumnos/as muy característicos y cuantos menos profesores intervengan en el progra- 
ma, más posibilidades de éxito tendremos Por el contrario, cuantos más profesores den clase en el programa, más problemas causaremos en nuestros alumnos/as ya que también será mucho más complicado y complejo la coordinación que ha de haber entre los diferentes profesionales del programa.

Al hilo de la coordinación, anteriormente indicada, tengo que decir que será esencial que el profesorado que imparte un mismo programa tenga los mismos $\mathrm{o}$, al menos, similares planteamientos en el ámbito pedagógico, metodológico y de disciplina. De lo contrario estaremos favoreciendo la existencia de conflictos en el grupo. Un elemento a tener en cuenta, es la pertenencia del profesorado al Departamento de Orientación. Otro aspecto a destacar y a tener en cuenta, desde Jefatura de Estudios, son los tiempos de los alumnos/as y profesorado.

En toda esta reflexión y toma de decisiones, es muy importante el papel que va a jugar el Equipo Directivo. Puede actuar como un elemento revulsivo o, por el contrario, como una rémora. Puede conseguir que el programa entre con muy bien pie en el organigrama del centro o, por el contrario, que todo el centro o parte de él esté en su contra.

No obstante, uno de los papeles más importantes, a la hora de planificar un programa de Garantía Social, radica en el Claustro de Profesores. Se ha de favorecer que se establezca en él un debate serio sobre el tema y que se dejen claras toda una serie de cuestiones para evitar malos entendidos

No podemos esperar que las soluciones vengan de fuera y por decreto. Hemos de ser nosotros quienes marquemos, de acuerdo a la ley, los caminos a seguir. $\mathrm{Y}$ uno de ellos es la Garantía Social. Pero, no podemos olvidarlo, es un paso más, no el único, aunque sí el último. Se ha de hablar en los claustros de agrupamientos flexibles, de refuerzos, de apoyos, de adaptaciones no significativas individuales o grupales, de adaptaciones significativas, de compensatoria, de diversificación y de garantía social. $\mathrm{Y}$ todas estas estrategias han de nacer de los propios claustros como consecuencia de una reflexión seria y coherente sobre los grandes problemas que todos, alumnado y profesorado, tenemos en nuestros centros. Unos problemas que no son ni más grandes ni más pequeños que antes. Son los mismos pero, después de muchos años de reflexión, hemos llegado a la conclusión de que era necesario buscar estrategias, organizaciones y estructuras diferentes para intentar solucionarlos. Si el claustro no participa, de manera directa o mediante los correspondientes departamentos, en estos temas estaremos sembrando, sin lugar a dudas, el fracaso del sistema, de éste u otro que, antes o más tarde, llegará.

Al hablar de los Departamentos, tenemos que indicar su papel esencial en todo lo citado anteriormente. Hay que favorecer la discusión y el debate en los departamentos que se encuentran, en mi opinión, demasiado obsesionados por temas que no son relevantes en estos momentos. Actualmente, cada departamento ha de pensar en algo tan simple y tan complicado a la vez como es la forma de llevar a cabo una atención a la diversidad de intereses, motivaciones y capacidades de los alumnos/as que tenemos en nuestras aulas. Y de todo ello ha de salir una serie de medidas que, analizadas con profundidad en la Comisión de Coordinación Pedagógica, dé como resultado todo un inventario de estrategias que como centro vamos a llevar a cabo. Las estrategias a utilizar nacen así del consenso y no de la imposición por parte de ningún sec- 
tor, sea del centro o de la Administración. En el caso de la Garantía Social es clave el funcionamiento del Departamento de Orientación. Éste supone un elemento importante de apoyo y ayuda. Tanto la figura del Psico-pedagogo como la del Trabajador Social son fundamentales una vez que el programa inicia su andadura.

En definitiva, si tenemos en cuenta todos los aspectos reseñados a la hora de planificar este tipo de programas estaremos sentando la base para que aquel sea un verdadero éxito.

\section{Perfil del alumnado. Implicaciones educativas}

Todos los alumnos/as que son sujetos de este tipo de programas se encuentran encuadrados en una de las etapas evolutivas más delicada y conflictiva. La gran mayoría de este alumnado se encuentra en la adolescencia. Resulta del todo imprescindible tener en cuenta este aspecto en la Garantía Social ya que nos va a marcar todo el desarrollo posterior de los citados programas.

Será imprescindible conocer qué supone para nuestros alumnos/as encontrarse metidos de lleno en la etapa de la adolescencia. Los maestros no podemos olvidar, bajo ningún concepto, la adolescencia con toda su problemática. A lo largo de estas páginas, vamos a encontrar un planteamiento de organización de los programas de Garantía Social, basado, como no podía ser de otra manera, en las características sicopedagógicas de los alumnos a los que va dirigido.

Un segundo aspecto, también muy importante, hemos de tener en cuenta a la hora de hablar de nuestro alumnado de Garantía Social. Estamos hablando de unos alumnos/as que, a las características como adolescentes, añaden otras, mucho más importantes posiblemente, que les han hecho llegar a la situación de requerir un tratamiento específico por parte del sistema educativo. Estas características especiales tienen que ver, sobre todo, con el ambiente familiar y social donde se han desarrollado.

Estas características generales las agrupamos especialmente en tres campos: comportamiento, aprendizaje y relaciones sociales. No obstante, antes de hacer un listado de dichas características, hay que dejar muy claro que estas son generales y que no quiere decirse con ello que todos los alumnos/as que acuden a un programa de Garantía Social participan de ellas.

En relación con los aprendizajes podemos afirmar, en líneas generales, que estos alumnos/as se caracterizan por:

- Desmotivación total hacia todo lo que suena a escuela.

- Hábitos de estudio muy deficientes.

- Grandes dificultades en la lectura y en la comprensión.

- Serias dificultades en cuanto a su capacidad de expresión oral y escrita.

- Han desarrollado más y mejor las destrezas manipulativas.

- Vocabulario escaso.

- Poca capacidad de sufrimiento.

En cuanto al comportamiento podemos decir que, en general, son:

- Conflictivos 
- Tienen serios problemas de autocontrol

- Impulsivos

- No soportan las normas impuestas por los mayores.

- Descentrados

- Sin continuidad en el trabajo.

- Apáticos

- Reaccionan de forma imprevisible.

En el tema de las relaciones sociales, en general, se caracterizan por.

- Odian todo lo impuesto por los mayores

- Es muy difícil de razonar con ellos.

- Se sienten muy bien con su grupo

- Su nivel de autoestima está muy bajo.

- Sus relaciones están basadas en puro materialismo

- Son muy consumistas

- Viven en un ambiente familiar problemático.

- Con roles muy marcados dentro del grupo

- La calle es su lugar preferido

- Pasan mucho tiempo ante la televisión

- Alto nivel de agresividad verbal y física.

Todo lo anteriormente expuesto, hemos de tenerlo en cuenta a la hora de plantearnos la posibilidad de trabajar en este tipo de programas. Nosotros, los profesionales, hemos de partir de todo ello para que este alumnado pueda desarrollar y avanzar. En muchas ocasiones nos vamos a encontrar con jóvenes muy capaces que, por razones muy diversas y que no vamos a enumerar, han pasado por la escuela sin haber logrado sus objetivos. Estos programas pueden ser su oportunidad y nosotros hemos de prepararles para que se puedan reincorporar al camino del que nunca debieron salir.

Así pues, teniendo en cuenta la etapa evolutiva en la que se encuentran y conocedores como somos de las características de los jóvenes sujetos de estos programas, hemos de reflexionar acerca de las implicaciones que todo ello ha de tener en el campo de la educación. Estas implicaciones deberían ser, en mi opinión, las siguientes.

- Hacer partícipe a los alumno/as en la organización de los diferentes aspectos que configuran el programa: curriculum, evaluación, actividades, disciplina, etc. Cuanto más participen los alumnos/as, mejor será la aceptación y asunción de los objetivos académicos. Esto repercutirá en un ambiente más disciplinado y más relajado.

- Establecer entre todos, profesorado y alumnado, el sistema disciplinario que ha de regir el buen funcionamiento del programa. En la medida que consigamos que los alumnos/as y el grupo acepte y lleve a la práctica este sistema, estamos haciendo una apuesta muy fuerte por eliminar la indisciplina de nuestra aula. 
- Procurar en el aula una metodología activa y participativa. Como decía un gran pedagogo: "Es mejor hacer que estudiar". Se aprende lo que se hace.

- El diálogo entre todos los miembros del programa ha de ser una constante. Este diálogo, ante todo, ha de ser sincero y claro. Olvidar este diálogo, es caminar hacia la indisciplina. Es fundamental en educación prestar mucha atención a la persona, pero en estos programas es la clave.

- La coherencia en la actuación será imprescindible. Pero para llegar a ello, está claro que nosotros, los maestros, hemos de ser un continuo modelo de coherencia.

- El nivel de exigencia a estos alumnos/as ha de ser progresivo. No se trata de bajar niveles, no se trata de exigirles menos que a otros, no se trata de entretenerlos. Hemos de exigirles más que a otros. Ahora bien, quizás hemos de exigirles otras cosas diferentes, sobre todo, en un primer momento. Tienen que empezar por conocer lo que es el esfuerzo y la satisfacción por la tarea bien hecha. Posteriormente, trabajaremos con ellos al máximo, puesto que han de recuperar el tiempo perdido.

- Hay que potenciar el grupo-clase. Para ello hay que facilitar la comunicación en el grupo sobre temas no académicos. Es necesario conseguir que el grupo asuma los objetivos y planteamientos generales del programa. Ello nos evitará todo tipo de conductas indisciplinadas. Es más fácil cambiar actitudes individuales por medio del grupo que directamente con el alumno/a. Este aspecto del grupo es muy importante. Por ello, en los programas de Garantía Social, hemos de cuidar mucho la dinámica del grupo, hemos de conocerla para modificarla y hemos de trabajarla desde el primer momento que llegue el grupo al aula.

- Los maestros/as debemos ser los líderes del grupo, pero un liderazgo no ganado por la autoridad que nos concede el cargo o la edad, sino basado en el prestigio que nos hemos de ganar a pulso, tanto dentro como fuera del aula. Si es así, con toda seguridad, tendremos escasos problemas de disciplina con nuestros alumnos/as.

Todo lo anteriormente citado pretende ser un resumen de aquellos aspectos que considero fundamentales para el buen funcionamiento de estos programas. Sobra decir que, en mi opinión, si esos mismos planteamientos se llevaran a cabo en las clases ordinarias, los resultados serían mucho más satisfactorios para todos, tanto alumnos/as como profesorado.

\section{El profesorado de Garantía Social. Su perfil}

No cabe duda que todos los elementos son importantes para que el funcionamiento de un programa de Garantía Social sea el correcto. Ahora bien, si yo tuviera que decidirme por uno de ellos, me quedaría, sin ningún tipo de titubeos, por el profesorado. Este es la clave de todo el programa.

En mi etapa como maestro he reflexionado mucho sobre la importancia que tiene el papel del profesor en la marcha del aula. Más cuando nos situamos frente a un colectivo con una problemática elevada, con una indisciplina continua y con unos 
hábitos y comportamientos inadecuados. Me atrevo a decir que trabajar con alumnos/as brillantes, no plantea generalmente muchos problemas. Sin embargo, trabajar con alumnos/as con problemas plantea serias dificultades, por lo cual los profesores que optan a ello han de saber, en primer lugar, eso y, en segundo lugar, han de estar dispuestos a dar todo de ellos mismos ya que se hace necesario cambiar, sobre todo, métodos de trabajo e implicarse de lleno en la tarea educativa y no tanto instructiva. No podemos dar a estos alumnos/as lo mismo que han estado recibiendo durante su escolaridad y que, además, tanto odian. No podemos enfrentarnos a ellos con la tiza y la pizarra. Debemos bajar a la arena de la clase en lugar de quedarnos en la barrera. Debemos hacer de guías y de compañeros.

Las características que un profesor/a debe cumplir para acceder a este tipo de programas, deberían ser, en mi opinión:

- Tener vocación de educador con todas las consecuencias que de ello se deriva.

- Creer en las personas y más concretamente en los adolescentes y en los jóvenes.

- Creer en lo que estamos haciendo.

- Comprender la problemática de la persona humana en su etapa como adolescente.

- Ser coherente consigo mismo, es decir, predicar con el ejemplo.

- Tratar a las personas con humanidad y con un total y absoluto respeto.

- Tener claro que quien tiene que motivar es el profesor/a. El alumno/a no está motivado de por sí.

- Todo y todos somos evaluables. La reflexión en grupo (Alumnos/as-Profesor/a) es el principio y el fin de todo el proceso educativo.

- Ser un maestro/a "democrático"

Creo que sobra hablar e interpretar cada uno de estas características. Están ahí para ser leídos y analizados con detenimiento. Son el principio de todo lo demás. Cada uno de ellos lleva implícito una serie de actuaciones en el programa y con los alumnos/as.

En principio y en teoría, todos son asumibles, lógicamente. Pero el problema se plantea cuando hay que pasar a la acción. Con todos los alumnos/as y, sobre todo, con los de estos programas, hemos de intentar cumplir al máximo con estos principios, de lo contrario correremos el peligro de que, en un desliz, todo el trabajo realizado hasta ese momento no haya servido de nada. De todas las formas, hemos de saber ser humildes y reconocer, si así ha sido, nuestros propios errores ante ellos y ellas. Si actuamos de esta manera, habremos recuperado rápidamente el camino perdido.

Todas las características citadas anteriormente han de ser puestas en práctica en el momento de iniciar la andadura de cada programa. Podemos hablar mucho de filosofía de la educación, nos podemos Ilenar la boca de metodologías activas y participativas, podemos engañarnos a nosotros mismos, pero no a los alumnos/as.

\section{Pincipios educativos y pedagógicos}

A partir de este capítulo, los planteamientos que voy a realizar tienen que ver ya con la parte más concreta de estos programas que es su puesta en práctica. Ha sido 
mi pretensión, dar forma escrita y teorizar sobre todo aquello que realizo en el aula y que a mí me ha servido. Antes de nada, quiero manifestar que, para llegar hasta aquí, he reflexionado y sigo reflexionando mucho junto a mis alumnos/as y con otros compañeros que me han asesorado y animado a seguir en este camino. Así pues, estas ideas son un análisis sobre todos los aspectos que, de una u otra manera, inciden en la puesta en funcionamiento y buena marcha de estos programas. Mi intención es manifestar de la forma más sencilla e inteligible todos los puntos y claves que, en mi opinión, se han de tener en cuenta al hablar de la organización y programación de unidades didácticas.

\section{1 Motivación, eje central}

Seguramente todos estamos un tanto hartos de escuchar siempre la misma frase: "Los alumnos/as no están motivados". Por otra parte, justificamos cualquier desastre en la evaluación de cualquier alumno/a o clase afirmando sin más, que carecen de la más mínima motivación. Los teóricos y no teóricos de la educación estamos de acuerdo en que la motivación es uno de los aspectos claves en el éxito académico de nuestros alumnos/as. Si estuvieran motivados, lo conseguirían todo. Ahora bien, actuamos como si pensáramos que la motivación ha de ser algo consustancial al alumno/a. Actuamos como si pensáramos que ellos son los que han de motivarse por sí mismos. Digo como si pensáramos, porque estoy convencido que todos somos conscientes de que quienes tenemos que motivar a los alumnos/as somos nosotros, los profesores/as y los maestros/as. Siempre existe un porcentaje de alumnos/as que están motivados de por sí. Pero tenemos en nuestras aulas otro porcentaje, mayor sin duda, que carece de ella. Con aquéllos resulta cómodo trabajar. Con éstos resulta mucho más complicado. Con aquéllos, en general, no cabe la indisciplina. Con éstos hay, en muchos casos, serios problemas disciplinarios. Los alumnos/as que son objeto de programas de Garantía Social pertenecen, por norma general, al segundo grupo, es decir, son alumnos/as muy poco o nada motivados con los temas escolares. Así pues, es necesario que tengamos muy claro, antes de empezar, que la clave para el éxito está en la motivación que logremos despertar en ellos y ellas.

Es muy fácil hablar de motivación. Es muy sencillo decir que hay que motivar. Pero es muy difícil y complejo llevarlo a la práctica. Y todavía es más difícil lograr que todos los alumnos/as estén motivados. No obstante, estos programas tienen una ventaja sobre el resto. No podemos olvidar que los alumnos/as acuden voluntariamente a ellos. Esta voluntariedad supone una cierta presión para ellos. En principio, se han comprometido con nosotros a seguir el programa de actividades. Por ello es muy importante, desde el primer momento, hacer hincapié en este detalle. Todo esto hay que dejarlo muy claro a las familias y a ellos en la primera entrevista que tenemos al iniciar el curso. Lógicamente, eso no es suficiente para que se encuentren motivados y con ganas de empezar su tarea. En la mayoría de los casos llevan excesivo tiempo sin sentirse atraídos lo más mínimo por los temas escolares. Por tanto hay que buscar una serie de estrategias que nos lleven a conseguir ese estado de motivación que les haga sentir la necesidad de saber y aprender.

Alcanzar ese punto de motivación es la primera tarea que nos hemos de marcar al hacernos cargo de un programa de Garantía Social. Para ello, es muy importante que 
nosotros, los maestros/as, estemos muy motivados en ello. Esa primera sensación de motivación y de interés que podemos dar a los alumnos/as los primeros días es un aspecto vital. Ellos buscan algo diferente de lo que hasta ahora han tenido en su escolaridad. Pues empecemos a dárselo. Están en una edad muy compleja. Necesitan modelos, pero modelos adecuados. Nosotros vamos a ser para ellos un elemento continuo de referencia, entre otras cosas porque vamos a pasar con ellos muchas horas.

La motivación no puede ser una actividad concreta y puntual que realizamos en un momento dado y que luego nos olvidamos. Los alumnos/as pueden sentirse muy motivados con dicha actividad, pero dejan de estarlo en el momento que pasamos al trabajo sistemático.

He reflexionado mucho sobre el tema y, al final, he llegado a la conclusión de que la motivación es todo. La motivación se ve implicada en todos y cada uno de los momentos que pasamos juntos. La motivación se encuentra en todas y cada una de las actividades. La motivación se manifiesta en cada uno de los que allí estamos. La motivación son formas pero también son contenidos. Por tanto, al hablar de motivación, estamos hablando de todo, de todas las cosas que nos rodean y de todas las personas que estamos implicados en estos programas: alumnos/as, maestros/as, padres/madres y comunidad escolar, en general.

Todo lo anterior, lo he agrupado, si así se puede decir, en seis grandes apartados o principios, si se me permite la licencia de darles este nombre. Estos son:

- PARTICIPACIÓN

- RELACIONES INTERPERSONALES

- METODOLOGÍA ACTIVA

- GLOBALIZACIÓN

- INTERDISCIPLINARIEDAD

- FUNCIONALIDAD DE LOS APRENDIZAJES

Cada uno de estos apartados o principios se han de hacer notar en el aula en los momentos oportunos, en los espacios adecuados, en las actividades concretas, en las actitudes de todos y cada uno de los miembros del grupo, en el sistema disciplinario a establecer, etc. Además los alumnos/as han de notar que se hace así. De otra forma, nos encontraremos con serias dificultades. No podemos crear en ellos, al comenzar el curso, unas expectativas que luego no seamos capaces de cumplir. Ello sería, sin lugar a dudas, lo más grave que nos podría suceder. Hemos de evitar en todo momento que se sientan traicionados por nosotros.

\section{2. Participación}

Al hablar de la motivación, he citado en primer lugar, como uno de los principios más importantes a tener en cuenta, el de la PARTICIPACIÓN.

No quisiera llenarme la boca con esta palabra y dedicarme a hablar sobre ella sin más. Voy a exponer una serie de estrategias y fórmulas que hacen efectiva y real la participación de los alumnos/as y padres/madres en los diferentes momentos del programa. Un axioma fundamental en educación nos dice que involucrar a los alumnos/as en el mayor número de cosas posibles, nos ayudará a tener un clima adecua- 
do en el aula. Pero no se trata solamente de crear un clima adecuado. Tenemos que ir más allá, tenemos que conseguir que nuestros alumnos/as adquieran una serie de hábitos y actitudes positivas hacia la participación en los diferentes momentos y espacios en los que se van a desenvolver a lo largo de su vida: asociaciones, movimientos culturales, etc. Ser partícipes en algo implica ser los responsables también de ese algo. Participar supone aprender a colaborar y cooperar junto a otros. La participación lleva consigo un alto componente de respeto a los demás. Aprender a participar incide en el aprendizaje de una serie de actitudes como tolerancia, saber escuchar, saber ceder, saber ganar y saber perder.

Ante este hecho, nos vamos a encontrar con una serie de alumnos/as que no saben participar porque, en muchas ocasiones y lugares, no se les ha permitido. La escuela no suele ser, en general, un lugar en que se permita a los alumnos/as participar activamente en muchas cosas, a lo sumo en elegir delegado de clase y representantes al Consejo Escolar. Esto no puede ser suficiente, hay que dejar al alumno/a participar en otros muchos momentos, tan importantes o más que en los anteriores. Esa es la forma de que aprendan. A participar se aprende participando. Por otra parte, en sus familias, casi con toda seguridad, tampoco se les ha enseñado a participar en grandes cosas. Estamos en un momento social en que todo se lo hemos dado hecho. Ellos no han participado en tomar ninguna decisión, en preparar cualquier tipo de actividad. Todo ello supone que nuestros alumnos/as carecen de una serie de hábitos y actitudes necesarios para participar de forma correcta en el programa. Por ello, hemos de tener en cuenta todo esto y promover poco a poco la participación en los diferentes momentos y aspectos. Nos vamos a encontrar con serias dificultades, al principio. Algunos alumnos/as no quieren participar. Unas veces por miedo al ridículo, otras veces porque no se sienten seguros y prefieren callar. En algunas ocasiones porque no les dice nada. Pero también nos encontraremos con alguno que no desea participar en nada porque en nada quiere responsabilizarse. Lógicamente, es más cómodo para ellos no participar. De esta manera siempre estará el maestro/a para culpabilizarle de todo lo negativo que suceda en el programa. En la medida que todos somos partícipes de todo, todos somos los responsables.

¿En qué pueden y deben, en mi opinión, participar los alumnos/as? Sinceramente, creo que en casi todo. Quizás decir todo no sería verdad.

Para empezar es muy importante para la buena marcha del programa que los alumnos/as participen en establecer la NORMATIVA del grupo. Estoy hablando del sistema disciplinario dentro del programa. Una vez establecido el sistema disciplinario, hay que crear una estructura que realice el seguimiento de dichas normas. Es la $A S A M B L E A$ el órgano que cumple dicha función. Otra estrategia que permite la participación efectiva y real de los alumnos, tiene que ver con los CARGOS UNIPERSONALES en el programa. Mucho les gusta a los alumnos/as participar en la PROGRAMACIÓN DE ACTIVIDADES. Lógicamente, no pueden participar en la programación de las unidades didácticas, pero sí pueden hacerlo en algunas de las actividades previstas en ellas. Han de sentir que tenemos en cuenta su opinión y una de las formas de lograrlo es mediante la programación y preparación de este tipo de actividades. Además, ellos nos pueden decir, de esta manera, aquellas cosas que más les motivan. No obstante, hay que estar a su lado, hemos de hacer continuamente de guías, pues de lo 
contrario se pierden. Este es un aspecto muy importante y que a muchos de ellos les puede venir muy bien de cara a su incorporación en determinadas asociaciones y grupos culturales.

El momento de la EVALUACIÓN es uno de los más serios del programa, tanto para ellos como para nosotros. Pues este es el momento crucial para hacerles ver que su participación es considerada muy importante, que es efectiva y que es real. Si hemos apostado por la participación, hay que ser valientes y enfrentarnos con ello. Todos los momentos en que realizamos evaluación los maestros, ellos también la han de realizar. Los alumnos/as han de participar en su propia evaluación. De esta manera, han de autoevaluarse en cada actividad realizada, pero sobre todo al finalizar cada una de las unidades didácticas. Los comienzos, como todo, son difíciles. No se lo toman en serio porque piensan que no sirve para nada. Pero cuando comprenden que eso va en serio y que se le tiene en cuenta, empiezan a ser más responsables con sus apreciaciones. Además, por lo general suelen acertar en sus diferentes calificaciones. Esta autoevaluación tiene su máxima expresión en el boletín de calificaciones que trimestralmente se les envía a casa. En él tienen un amplio apartado donde han de explicar a sus padres cómo ha sido el trimestre según su opinión. Intento que el boletín sea algo de todos, de ellos y nuestro. Evaluar al profesorado es para ellos muy interesante. En cada unidad didáctica han de hacer una valoración de los diferentes aspectos que conforman la tarea de educar. Valoran nuestras explicaciones, nuestra actitud, nuestro comportamiento e interés y nuestra motivación. También el programa en sí es evaluado por ellos. Cada trimestre hemos de hacer un balance del programa. En él pedimos la colaboración de los alumnos/as. Ellos, mediante el correspondiente cuestionario, nos dan muchas ideas que nos permiten modificar y corregir.

En pocas palabras, hay que favorecer la participación efectiva y real de los alumnos/as en todos y cada uno de los momentos del programa.

\subsection{Relaciones interpersonales}

De todos y cada uno de los aspectos o principios citados, se puede afirmar que son fundamentales. Pero, en este caso nos asiste la razón. Las relaciones interpersonales que se establezcan en el aula son muy importantes. Cuando hablamos de ello, estamos hablando sobre todo de las relaciones entre maestros/as y alumnos/as.

Desde el primer momento hay que establecer unas relaciones claras y marcadas. Cada uno de los que forman el programa ha de saber hasta dónde se puede llegar. No se trata de entregar la autoridad a los alumnos/as. No se trata de imponer la autoridad por razón de nuestro cargo. Hay que buscar el término medio, el equilibrio. El tema de la autoridad es uno de los más complejos en estos programas, no podemos olvidar nunca que estamos tratando con adolescentes con todo lo que ello conlleva, entre otras muchas cosas, de odio a la autoridad de los mayores, sean estos quienes sean. La autoridad debemos ganarla. Es la única solución posible. Son los propios alumnos/as quienes nos han de entregar, de forma simbólica, la vara de mando del programa. Para ello hemos de cumplir con una serie de condiciones que son muy importantes para ellos. Su momento evolutivo es difícil y necesitan alguien que les guíe. Ésa 
es nuestra tabla de salvación, somos nosotros quienes hemos de conseguir ser ese alguien que buscan desesperadamente.

\subsection{Metodología activa}

Cuando hablamos de actividad, estamos hablando de hacer. Hay una frase de un pedagogo que resume muy bien este principio: "Más vale hacer que estudiar".

Ahora bien no se trata de hacer por hacer. Hay que tener cuidado no convirtamos este principio en una actividad alocada sin ningún sentido. Eso se denominaría "entretenimiento", tener entretenidos a los alumnos/as sin más intención. La metodología activa requiere una alto componente de programación seria y adaptada a las necesidades de este tipo de alumnos/a. Se ha de evitar, sobre todo, la improvisación, que es mala consejera en educación.

Ese "hacer" ha de ir enmarcado en una programación seria y con unos objetivos muy claros a los que se ha de tender. Ellos serán siempre nuestra referencia. Todo el camino que hemos de realizar hasta ellos ha de estar bien planificado. Teniendo en cuenta lo anterior, hemos de intentar que los alumnos/as "hagan". Realmente nos encontraremos con serias dificultades con algunos de ellos ya que durante varios cursos han dejado de "hacer". Se han limitado a pasar el tiempo en las aulas sin realizar ningún tipo actividad y mucho menos han hecho algo en sus casas. Por tanto, hemos de cuidar mucho la puesta en práctica de nuestra programación y hemos de tener muy en cuenta este último aspecto, sobre todo a la hora de planificar los diferentes momentos del aula: exposición de conceptos, actividades, deberes, etc.

\subsection{Globalización}

Cuando hablamos de Globalización, estamos hablando lógicamente de un método de trabajo, de una determinada forma de presentación de la materia. No obstante, he querido separar este aspecto del anterior relacionado con la metodología activa porque lo considero muy importante en este tipo de programas y para darle un mayor realce.

En el plano teórico hemos oído hablar mucho de este método. El problema se plantea siempre con su puesta en funcionamiento dentro de un aula.

Cuando, allá por el año 1986, iniciamos la experiencia de Educación Compensatoria, nuestra primera tarea fue realizar el proyecto curricular que habríamos de trabajar con nuestros alumnos, ya fuera uno o dos años, según sus necesidades. Durante dos cursos anduvimos dando tumbos, aprendiendo de los propios errores y mejorando la propuesta. Pero llegó un momento, curso 1988, en que comprendimos que debíamos trabajar con un método diferente. Entonces decidimos profundizar, por medio del grupo de trabajo que teníamos, todo lo relacionado con la Globalización y la Interdisciplinariedad. Investigamos por nuestra cuenta, tuvimos charlas de expertos en el tema y, al fin, nos dispusimos a ponerlo en práctica en algunas de las aulas. Dentro de las posibilidades que nos ofrecía la Globalización, elegimos los Proyectos Integrados de Aprendizaje. Realizamos varias propuestas y las pusimos en práctica. Ciertamente, el hecho de contar con talleres polivalentes en las aulas 
de Compensatoria, favoreció su puesta en práctica. Los resultados fueron bastante positivos. La motivación de este tipo de alumnos/as aumentó considerablemente. Así hemos estado trabajando en algunos programas de Educación Compensatoria hasta la llegada de los programas de Garantía Social y, además, la desaparición de la Compensatoria tal y como la entendimos en aquellos momentos.

\subsection{La interdisciplinariedad}

No podemos olvidarnos, además, de otro elemento básico cuando hablamos de presentar las materias a los alumnos/as de una manera motivadora.

Esta es la INTERDISCIPLINARIEDAD

Al realizar la programación de cada una de las Unidades Didácticas es muy importante tener en cuenta este aspecto. Es muy interesante que los alumnos/as perciban que todo lo que se trabaja en las diferentes áreas está relacionado con lo demás y no sólo con el taller. Es una forma de hacerles comprender que, en la vida diaria, todo está relacionado.

En estos programas es relativamente fácil tener en cuenta este principio ya que, por regla general, es un mismo maestro/a quien se hace cargo de todo la Formación Básica. Por ello, puede establecer todas aquellas relaciones que considere oportunas. Hay que hacer mención especial en este momento a la importancia de que sea un maestro/a quien imparta la parte cultural. De lo contrario habrá una mayor dificultad para llevar a buen término el tema de la interdisciplinariedad ya que obligaría a realizar un esfuerzo suplementario al tener que dedicar un tiempo a la coordinación que de otra forma, si sólo es un profesor, se elimina.

Con relación al tema que nos ocupa, he ido trabajando a lo largo de los dos últimos cursos. En este sentido, he desarrollado dos Proyectos Interdisciplinares uno de los cuales lo pusimos en práctica el curso 96/97 consiguiendo un rotundo éxito a todos los niveles. Este proyecto lo llevamos conjuntamente los dos maestros del programa, algo fundamental para poder trabajar con este tipo de planteamientos. Ello nos permitió poner, como centro de todo el proyecto, al taller de fontanería, con lo cual la motivación de los alumnos estaba conseguida de antemano. El citado proyecto se tituló "TODOS A REGAR". Su finalidad era instalar un sistema de riego por goteo en unas fincas de árboles frutales en un centro de Educación Especial de Logroño. Dicho proyecto nos llevó dos meses de trabajo, repartidos en tres momentos: ANTES DE... , DURANTE... Y DESPUÉS DE LA INSTALACIÓN. Los resultados fueron asombrosos.

\subsection{Funcionalidad de los aprendizajes}

Se trata, sobre todo, de que todo lo que los alumnos/as vayan a aprender en el curso, les sirva. Durante su escolaridad, sobre todo los últimos cursos, han estado trabajando muchas cosas y aspectos, que no les invitaban a nada. Estos programas no se pueden permitir el lujo de volver a caer en el mismo error. Sería perder un tiempo muy importante para ellos. Hay determinados aspectos, procedimientos y actitudes que, antes de salir al mundo laboral, han de alcanzar. Por ello se han de buscar aquellos 
aprendizajes que, realmente, se consideran importantes $y$, sobre todo, funcionales, que les sirvan.

\section{Propuesta curricular. Principios para la elaboración de las unidades didácticas}

En este capítulo, se pretende dar una respuesta al interrogante de ¿qué hacer en un programa de Garantía Social? En la Orden de 12 de Enero de 1993, en el apartado undécimo, punto 4, dice con relación a este tema:

"El Ministerio de Educación y Ciencia pondrá a disposición de los Centros y Entidades señaladas en el apartado anterior las propuestas curriculares y la documentación de apoyo necesaria para la elaboración de las citadas programaciones."

Conocida la propuesta curricular del MEC era necesario sentarse a desarrollarla para hacerla efectiva en nuestra aula. Esto es lo que verdaderamente supone mucho trabajo, bastante esfuerzo y, sobre todo, excesivo tiempo para ser abordado por una única persona. Sin embargo, aquellos que iniciamos nuestra andadura por la Garantía Social desde sus inicios tuvimos que llevarlo a cabo de forma individual por carecer, incluso, de compañeros con los que compartir ese tiempo, al empezar solos esta aventura. Sin embargo, me puse manos a la obra y el resultado está ahí: siete Unidades Didácticas, un Proyecto Interdisciplinar y un Cuaderno de Prácticas.

En el momento de plantearme la elaboración de las diferentes Unidades Didácticas, debía tener en cuenta, como no podía ser de otra manera, todo lo que hasta este momento he señalado. En resumen, se puede decir que los principios que he tenido en cuenta en su elaboración han sido los siguientes:

- Lo que tenía muy claro, al elaborar las unidades didácticas, era que debía plantearlas de acuerdo al principio de la Globalización e Interdisciplinariedad. No podía dar a estos alumnos las mismas cosas que en sus aulas anteriores y, lo más importante, de la misma forma y con la misma metodología.

- Por otra parte, tenía muy claro, y la experiencia en Compensatoria durante ocho años me lo decía, que los contenidos que debía trabajar con ellos habían de ser, sobre todo, funcionales.

- No podía olvidar, lógicamente, la situación de partida de estos alumnos en cuanto a su problemática personal, familiar y social.

- Era totalmente imprescindible partir de lo que ellos sabían en las diferentes materias que constituían el área de Formación Básica.

- Era fundamental, con estos alumnos, trabajar los contenidos de tipo procedimental y actitudinales, siendo secundarios los conceptuales a los que deberían llegar, en su caso, de forma inductiva .

- Era primordial, para que funcionase el programa, hacer a los alumnos partícipes en la programación de actividades y en su organización.

- Estaba claro que las relaciones personales (alumnos-profesor, alumnos-alumnos) iban a ser la clave de la buena marcha del programa.

- Estaba claro que la metodología debía de ser, entre otras cosas: Activa. 
- El entorno sería un referente continuo en la programación de las diferentes unidades.

- En fin, era totalmente imprescindible motivar a los alumnos, ya que ellos de por sí no lo están.

\section{Tutoría y acción tutorial}

Al hablar de Tutoría, en los tiempos que corren, podemos pensar en una hora lectiva que todos los grupos de alumnos/as de Secundaria han de tener en su horario. Por otro lado, podemos creer que Tutoría es una hora lectiva que los Tutores de los diferentes grupos de Secundaria han de dar a sus alumno/as. Podemos afirmar que Tutoría es la hora que dedicamos a trabajar con los alumnos diferentes actividades que nos programa el Departamento de Orientación y que está muy bien recogido en el plan de Acción Tutorial de cada centro en cada curso escolar. Todo ello es Tutoría.

Cuando hablamos de Tutoría en un programa de Garantía Social, podemos creer esas mismas cosas. Sin embargo, llama la atención que en estos programas el número asignado a esta materia, si así se puede denominar, por parte del MEC son dos horas. Esta simple observación viene a demostrarnos que la Tutoría en estos programas está concebido como algo especial, como algo fundamental, como algo importante. Por todo ello, cualquier maestro/a que se haga cargo de un programa de Garantía Social ha de tener esto muy claro, de lo contrario puede tener ciertas dificultades que, poco a poco, pueden transformarse en serios conflictos.

Después de cuatro años en un programa de este tipo, me atrevo a afirmar que la Tutoría va más allá de las dos horas lectivas recogidas en el horario del alumnado y profesorado. La tutoría ha de pasar a ser lo que podríamos denominar Acción Tutorial. Entiendo por Acción Tutorial todo aquello que se realiza en el aula y fuera de ella, realizado por cualquier miembro de la comunidad educativa, perfectamente programado y calculado y que va en beneficio del alumnado como persona íntegra. En resumidas cuentas, considero que la tutoría ha de extenderse a todos los momentos y a todas las actividades que se programan en el aula. En líneas generales y teniendo en cuenta todo lo anterior, podemos decir que la acción tutorial tiene tres objetivos bien claros y que son el fundamento del programa, especialmente:

- Conocer al alumnado en sus diferentes dimensiones y aspectos, personal, familiar y social, con el fin de ayudarles.

- Favorecer la madurez personal de nuestros alumnos/as

- Orientarles acerca de su futuro académico y/o profesional.

"Desarrollar y afianzar su madurez personal, mediante la adquisición de hábitos y capacidades que les permitan participar como trabajadores y ciudadanos responsables, en el trabajo y en la actividad social y cultural"

(Cuarto, c del 12 de Enero de 1993)

Si desmenuzamos este artículo de la citada orden, hablaremos de muchos de los aspectos que han ido apareciendo a lo largo de este trabajo y que he citado como ele- 
mentos importantes a tener en cuenta a la hora de poner en marcha un programa de Garantía Social. Estamos hablando de madurez, de participación, de responsabilidad, de hábitos, de capacidades, de trabajadores, de ciudadanos, de libertad. Todo esto se logra mediante un sistema de trabajo donde se conjugan todos esos elementos.

Se aprende lo que se hace, por lo tanto en nuestros programas, para lograr esa madurez personal con todo lo que ello supone, lo hemos de poner en práctica a diario. No sirve la lección magistral acerca de lo que es la responsabilidad, sino que hemos de conseguir que nuestros alumnos/as se responsabilicen de algunas cosas. No sirve la lección magistral sobre la participación, sino que hemos de conseguir que nuestros alumnos participen en todos y cada uno de los momentos del programa. No sirve la lección magistral acerca de la libertad, sino que hemos de buscar que el alumno actúe con libertad que es lo mismo que actuar con responsabilidad.

\subsection{Conocer}

Al citar los objetivos de la tutoría, en primer lugar he hablado de "CONOCER" al alumnado con el único de fin de ayudar en su desarrollo personal y social.

Lógicamente lo primero que se ha de acotar son los aspectos que hemos de conocer de nuestros alumnos. En este sentido, considero que hay tres aspectos que debemos intentar conocer si de verdad buscamos ayudarle: ALUMNO, ENTORNO Y GRUPO. En el anexo no 1 podemos encontrar todos aquellos aspectos que, en mi opinión, debemos conocer de nuestros alumnos/as, así como las estrategias para el descubrimiento de los mismos. El conocimiento de nuestro alumnado traerá como consecuencia el descubrimiento de todo un abanico de problemas que hemos de empezar, desde el primer momento, a intentar dar solución o ir derivando a las personas o instituciones que así pueden hacerlo. (ANEXO № 1)

\subsection{Problemas y actuaciones}

Todo el trabajo desarrollado anteriormente trataba de conocer a nuestros alumnos/as y detectar aquellos problemas que deberíamos intentar abordar y solucionar a lo largo del curso escolar que dura nuestro programa. Como primer elemento de reflexión podemos señalar que es tal el cúmulo de problemas que en un curso escolar bien poco podemos hacer. Ahora bien, aun siendo conscientes de ello, esto no nos exime de trabajar con gran dedicación para poner las bases a fin de que nuestros alumnos/as se hagan conscientes de su situación y poner en sus manos las estrategias adecuadas para que, entre todos, vayamos reconstruyendo ese edifico que es la persona humana.

En resumen, no se trata tanto de que nosotros apaguemos pequeños fuegos, como de enseñar a nuestros alumnos/as, primero a no provocarlos y, por último, a saber apagarlos a tiempo, bien por ellos mismos bien sabiendo los pasos a seguir. Los problemas con los que nos vamos a encontrar a lo largo del curso son muchos. Yo los he intentado agrupar con el fin de reflexionar sobre ellos y sobre las soluciones que, en nuestro caso, hemos ido dando, dejando bien claro que pueden existir y existen otros problemas diferentes, propios de otros tantos grupos de Garantía Social, así como otras soluciones, también diferentes a las que hemos dado en nuestro caso. Todo ello está basado en la experiencia personal y en la reflexión acerca de todo ello. (ANEXO № 2) 
Anexo I
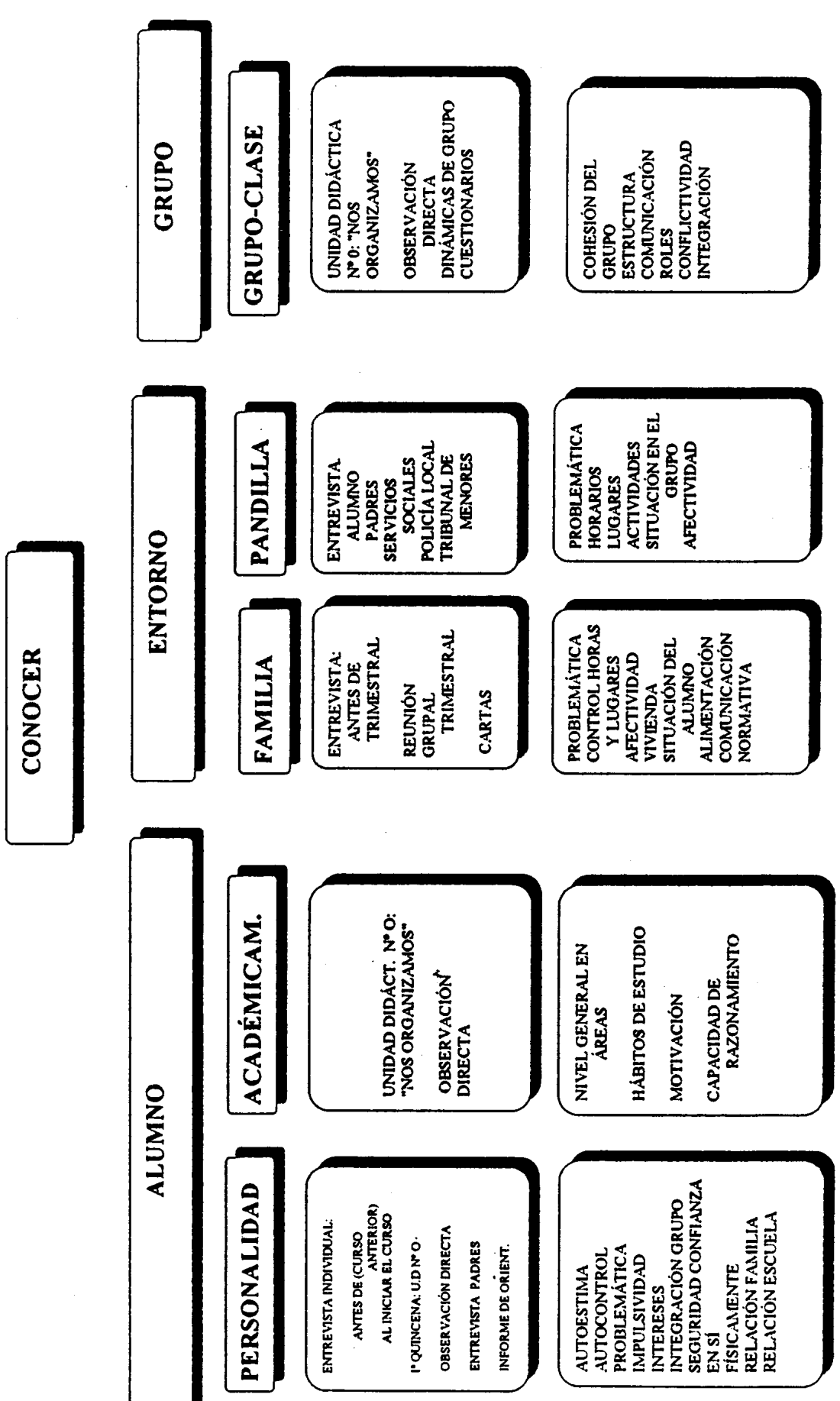

倠

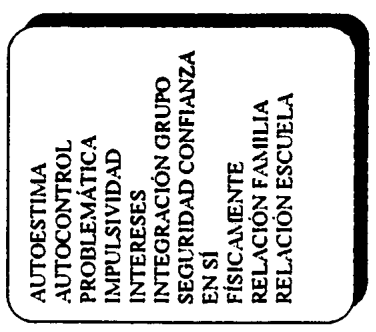


Anexo II
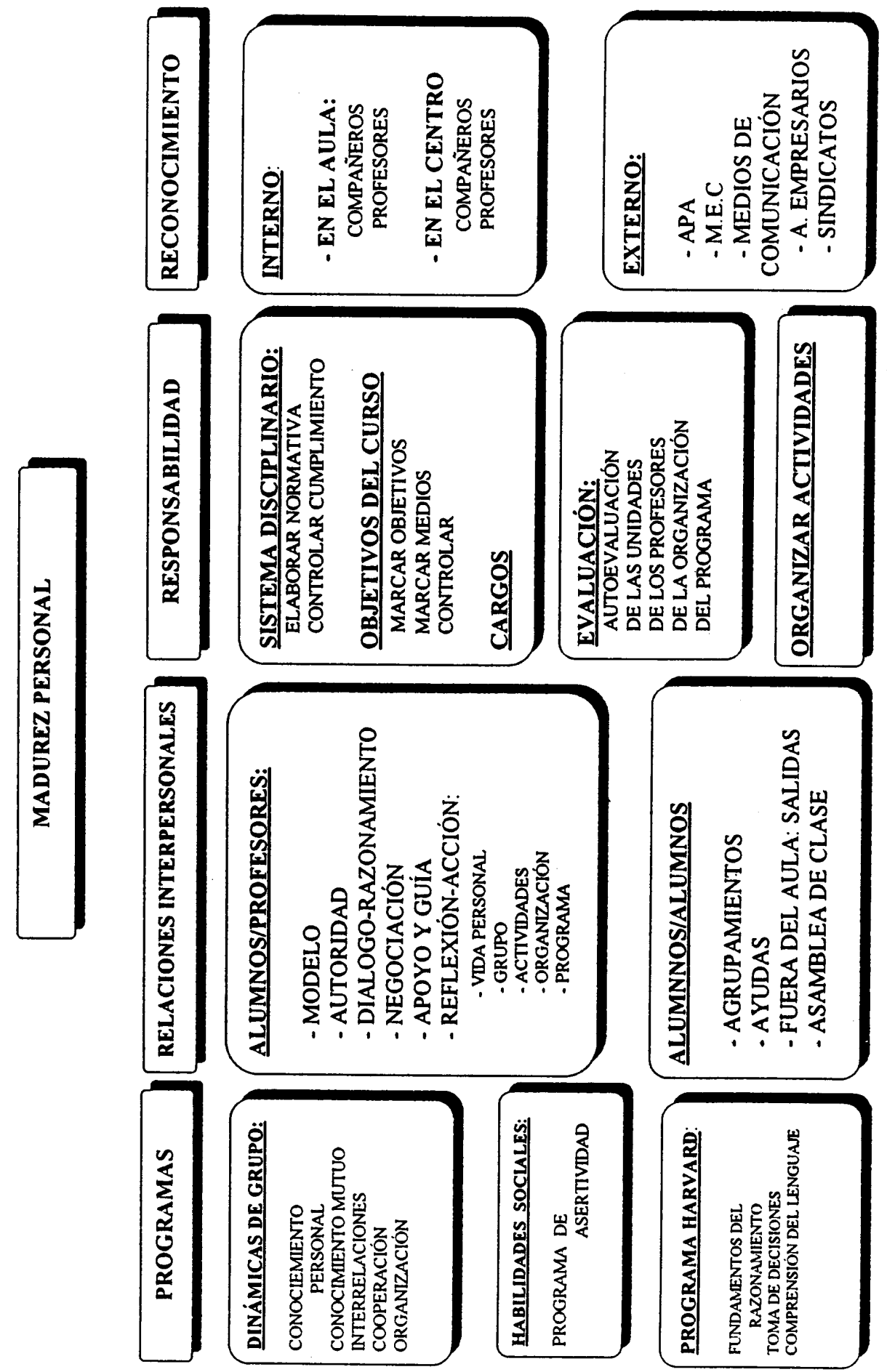
Anexo II
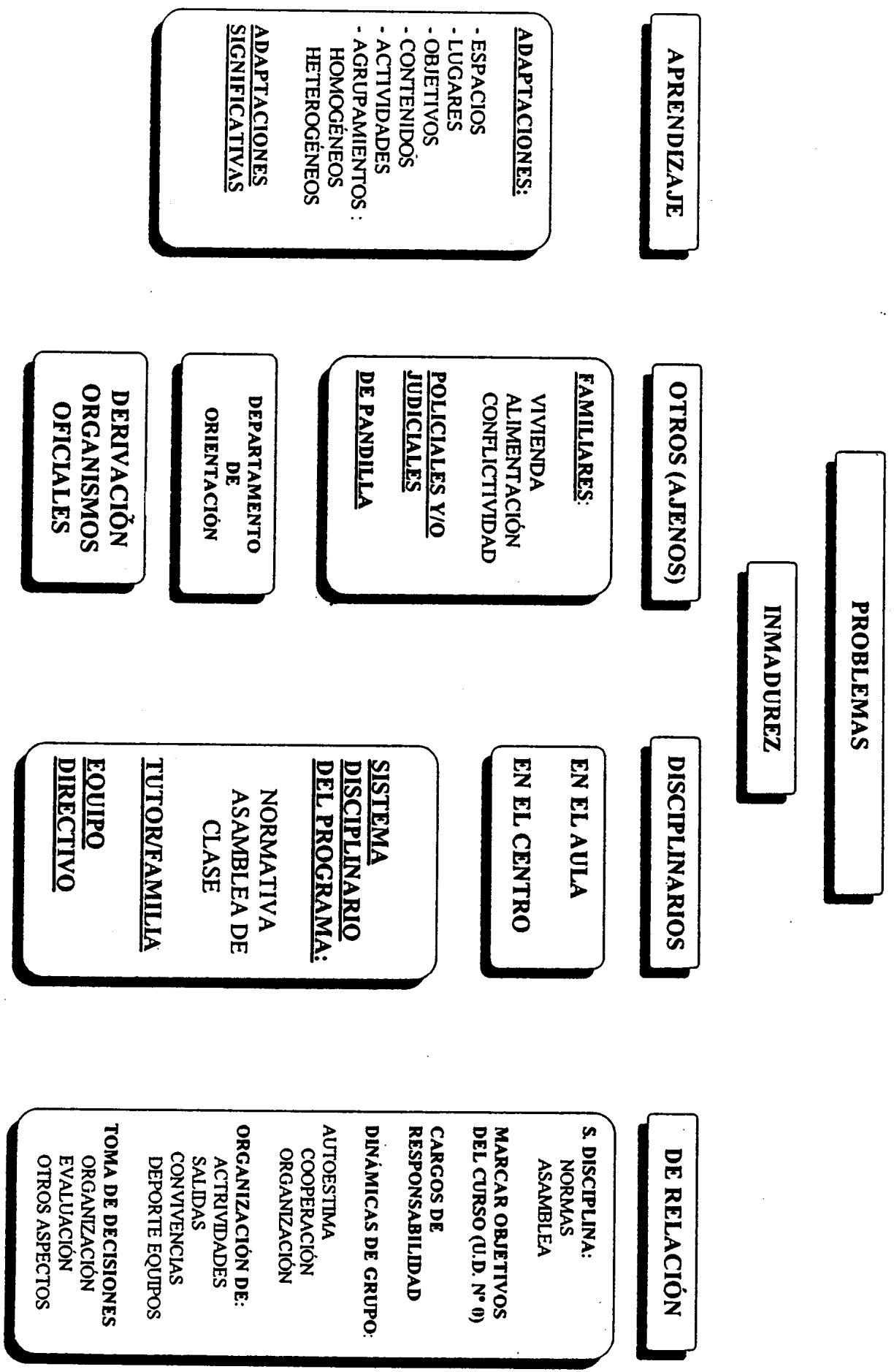


\section{Inserción Laboral}

La finalidad de estos programas, tal y como queda recogido en la orden del 12 de enero de 1993 y que ya hemos comentado, es facilitar la incorporación de estos alumnos en el sistema educativo o bien posibilitar su acceso a un puesto de trabajo.

En cuanto al tema de su inserción en el mundo laboral, quiero plasmar de forma clara todo lo que, desde el programa y centro, se ha realizado con el fin de favorecer dicha inserción.

Lógicamente, en el área de Formación y Orientación Laboral (FOL) se realiza una serie de actividades encaminadas a ello. Me estoy refiriendo al bloque que denominamos "TÉCNICAS DE BÚSQUEDA DE TRABAJO". Son actividades de aula y realizadas por los propios alumnos/as. Pero en el tema que nos ocupa, desde el centro y desde el programa, hemos elaborado y llevado a cabo un plan previamente establecido. Este plan se ha ido cumpliendo desde el primer momento en que empezó su andadura nuestro programa. Los resultados obtenidos se pueden considerar de muy satisfactorios para todos, alumnos/as, centro y empresas.

En líneas generales, el plan que hemos establecido y que puede ser exportado a cualquier otro programa que se inicia, como estamos haciendo en estos momentos, sería el siguiente:

a) ENTREVISTAS:

El primer año que iniciamos este programa llevamos a cabo multitud de entrevistas con el sector empresarial y sindical del mundo del Metal. Se trataba de que, en primer lugar, conocieran la existencia de nuestro programa y su finalidad. Entramos en contacto con la Federación de Empresarios de La Rioja que nos derivó a la Asociación correspondiente, en este caso, denominada AFONCAGAS. Tuvimos muchos contactos y entrevistas con los responsables de la citada asociación. Conseguimos su compromiso para favorecer entre sus asociados la realización de las correspondientes prácticas en empresas. Éstas se han realizado hasta el presente curso escolar sin ningún tipo de problemas. Asimismo, la asociación dio a conocer el programa a todas las empresas asociadas. Este contacto se mantiene en cada curso escolar con visitas a su sede con el fin de que los alumnos/as sepan de su existencia ya que, por otro lado, pueden realizar en ella cursos de formación una vez terminado el programa de Garantía Social.

\section{b) CARTA Y BOLSA DE TRABAJO:}

Una vez establecidos los primeros contactos durante el primer año, en los cursos posteriores se trata de mantenerlos. Para ello, en cada curso escolar, la primera tarea a realizar en relación con la inserción laboral es redactar y enviar una carta a todas las empresas del sector con el único fin de recordarles nuestra existencia.

Esta carta busca dos cosas principalmente. Por un lado, recordar que es preciso iniciar la preparación de las prácticas y, por otro, poner a su disposición la "BOLSA DE TRABAJO" existente en nuestro centro. Esta bolsa de trabajo, que viene funcionando desde el segundo año, tiene como finalidad la inserción laboral de los alumnos/as que han pasado por nuestro programa. A lo largo de estos años, varios alumnos/as han 
encontrado su puesto de trabajo con esta fórmula. Consiste simplemente en la existencia de una lista de los alumnos/as que han pasado por el programa y no tienen trabajo. Esta lista viene ordenada por calificaciones y se trata de poner en contacto al empresario con el alumno/a que se encuentra en el primer lugar de la lista. Generalmente las empresas buscan obreros en el INEM o ETT, nosotros les ofrecemos jóvenes que tienen, al menos, una mínima cualificación en el sector y que, por lo tanto, no tienen que empezar con ellos desde el desconocimiento total y absoluto de la profesión

\section{C) PRESENTACIÓN DE ALUMNOS/AS:}

El tercer paso que damos en este plan es la presentación de los alumnos/as en las empresas. A lo largo del primer trimestre trabajamos algunas de las técnicas de búsqueda de trabajo y preparamos a los alumnos/as en aspectos tan importantes como la presentación y la entrevista. Durante las vacaciones de Navidad llega el momento de poner manos a la obra. Cada alumno/a se compromete a presentarse a un número determinado de empresas con el fin de comprobar que la carta ha llegado y buscar un compromiso oral, si es posible, con la citada empresa para poder realizar en ella sus prácticas. En algún caso, ciertos alumnos/as han encontrado la posibilidad de trabajar, incluso. De esta manera, hacemos una selección previa de aquellas empresas que están dispuestas a la colaboración y aquellas con los que nos va a resultar más complicado.

\section{d) PRESENTACIÓN DE PROFESORES:}

Una vez visitadas las empresas por los alumnos/as y conocidas aquellas que han sido receptivas a nuestra propuesta, entramos en contacto con ellas de una manera directa. El responsable de prácticas se presenta en dichas empresas en nombre del Centro y del Ministerio de Educación y Cultura. En esta entrevista se informa de una manera más profunda sobre todos los aspectos que rodean a este tipo de programas. Se habla de las prácticas y de su organización, se habla de la bolsa de trabajo y sus posibilidades y se busca que la citada empresa se haga colaboradora nuestra mediante la firma de un Convenio para que nuestros alumnos/as puedan realizar allí las prácticas correspondientes. Los resultados hasta ahora son satisfactorios.

\section{e) VISITAS A EMPRESAS:}

A lo largo de los cursos se van manteniendo de forma periódica estos contactos que obviamente no se pueden perder. Especialmente se llevan a cabo visitas a la empresas con convenio en el segundo trimestre, cuando comenzamos la preparación de la fase de prácticas. Estas visitas las realiza generalmente el responsable de las prácticas.

Por otro lado, en la fase de prácticas, el tutor de las mismas, en nuestro caso el Maestro de Taller, gira al menos dos visitas a cada una de las empresas donde el alumno/a está realizando sus prácticas. Es un buen momento para tomar nota acerca no sólo de los alumnos/as sino de aquellas cuestiones que pueden resultar importantes para el programa. Este contacto nos puede hacer incluir ciertas modificaciones en la 
programación, nos puede hacer comprender que es necesario profundizar en algunos aspectos o que tenemos que eliminar otros, etc.

Lógicamente, llevar a cabo este plan requiere mucho tiempo y mucho esfuerzo. Es importante que la administración correspondiente sea consciente de ello y hemos de hacérselo saber. Este es el momento, porque nos encontramos en una fase de experimentación, por así decirlo. Prestar un servicio de calidad no se puede hacer sin una dedicación de tiempos suficientes. La situación actual es muy delicada. Estamos en el punto clave para que estos programas tomen un rumbo donde prime la calidad o, una vez más, sean un simple parche que nos permita decir que se está haciendo algo pero sin un convencimiento de que se está haciendo bien.

Hasta ahora, por mi experiencia en este campo, puedo decir que los resultados, en cuanto a la inserción laboral se refiere, son muy satisfactorios. Podemos hablar de que en los dos años siguientes, hasta que los jóvenes son llamados a cumplir el servicio militar, que es el tiempo que los controlamos, hay un $65 \%$ de alumnos/as que encuentran trabajo y, también hay que decirlo, en la mayoría de los casos en las empresas donde hicieron sus prácticas. Esto nos demuestra lo importante de organizar y programar convenientemente esta fase del curso de Garantía Social.

\section{Bibliografía}

ÁBALO, VALENTÍN Y BASTIDA FRANCISCO. (1994). "Adaptaciones Curriculares", Editorial Escuela Española.

ALBERICIO, JUAN JOSÉ. (1991). "Educar en la diversidad", Editorial Bruño

ARNAIZ, PERE Y ISUS, SOFÍA. (1995). "La tutoría. Organización y tareas", Editorial Graó.

BRANDEN, NATHANIEL. (1994). "Cómo mejorar la autoestima", Editorial Paidós.

BRUNET GUTIERREZ, JUAN JOSÉ Y NEGRO FAILDE, JOSÉ LUIS. (1988). “Tutoría con adolescentes", Editorial San Pío X

CALVE MANZANO, JOSÉ LUIS Y GARCíA PÉREZ, E. MANUEL. (1992). “La Acción Tutorial", Editorial CEPE

CURWIN, R.L. Y MENDLER, A.N. (1987). "La disciplina en clase", Editorial Narcea.

DIEZ GUTIÉRREZ, ENRIQUE JAVIER. (1995). "Diseño curricular de Garantía Social", Ediciones Pedagógicas.

ESCAMILLA, AMPARO. (1993). "Unidades Didácticas: una propuesta de trabajo de aula", Editorial Edelvives.

PUIGDELLiVOL, IGNASI. (1993). "Programación de aula y adecuación curricular", Editorial Graó.

SÁNCHEZ, SERAFíN. (1993): "La tutoría en los centros docentes", Editorial Escuela Española. 